\title{
Glucose transporter 4 gene expression in peripheral blood leukocytes in type 2 diabetes mellitus
}

\author{
Shahana Jasmin, Mohammad Ali, Mokerroma Ferdous, M. Iqbal Arslan and Subrata K. Biswas
}

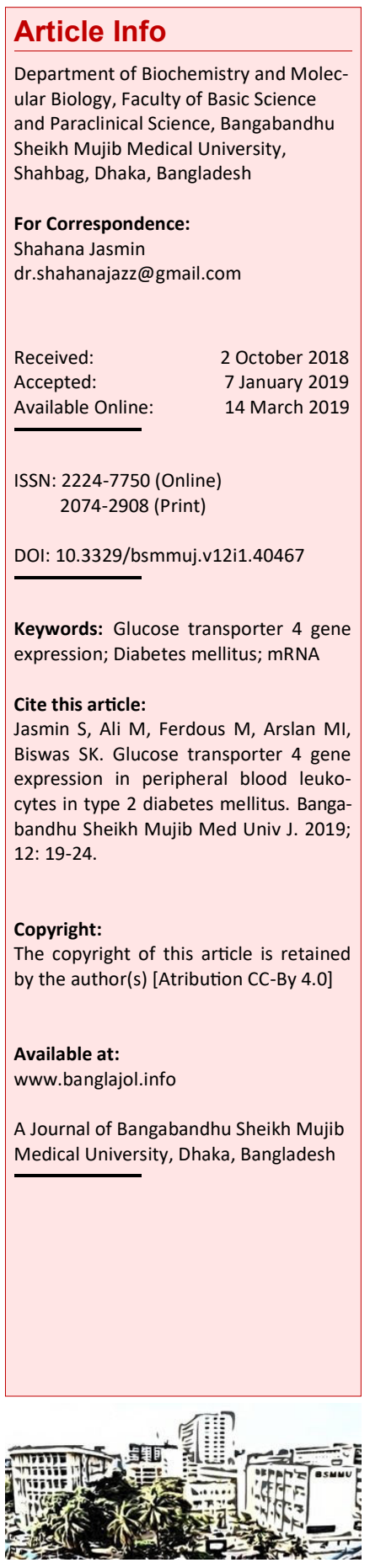

\section{Abstract}

The purpose of this study was to examine the status of glucose transporter type-4 (GLUT4) gene expression in the peripheral blood leukocytes of type 2 diabetic patients and explore the correlation of GLUT4 expression with homeostasis model assessment-insulin resistance with a view to validate GLUT4 as a relatively less invasive alternate marker for insulin resistance. A total of 48 subjects were recruited. Among them, 23 subjects were diabetic and 25 were age, sex and body mass index-matched non-diabetic healthy control subjects. Insulin resistance, beta cell function and insulin sensitivity were assessed from the fasting blood samples. The mRNA levels of GLUT4 gene in the peripheral blood leukocytes were quantified by reverse transcriptase PCR. There was no significant alteration of GLUT4 gene status between type 2 diabetes mellitus and control. The GLUT4 gene expression showed a negative trend in the relationship with fasting glucose, HbA1c, insulin and insulin resistance in diabetic patients. In conclusion, the GLUT4 gene expression in the peripheral blood leukocytes cannot be used as a marker of insulin resistance.

\section{Introduction}

Type 2 diabetes mellitus is a chronic, progressive, and multifactorial metabolic disease defined by the presence of chronic hyperglycemia. The effects of diabetes include longterm damage, dysfunction, and failure of different organs, especially the eyes, kidneys, nerves, heart, and blood vessels. 1 Impaired insulin secretion (due to $\beta$-cell dysfunction or loss of $\beta$-cell mass) and increased insulin resistance are the main pathophysiological features responsible for the development of hyperglycemia in type 2 diabetes. 1 Identification of the predominant defect, whether it is insulin resistance or $\beta$-cell dysfunction, can help select appropriate antidiabetic agents. Moreover, assessment of insulin resistance status is important to study the longitudinal effect of the intervention (with drug, diet or exercise) on insulin resistance. The assessment of true status of insulin resistance requires invasive procedure - euglycemic-hyperinsulinemic glucose clamp, which is experimentally demanding, complicated, and impractical when large scale epidemiological studies are involved. These methods are laborious, painstaking and expensive, and therefore, rarely used in large-scale clinical research and never used in clinical practice. So, a number of surrogate indices for insulin sensitivity or insulin resistance have been developed. Among the surrogate markers homeostasis model assessment-based insulin resistance is commonly used because of its simplicity.2 But it has been shown that homeostasis model assessment-based measure of insulin resistance cannot identify the true status of insulin resistance for certain situations like longitudinal interventional studies.., 4 So, it is necessary to develop another accurate yet relatively simple measure of insulin resistance.

The major route for disposal of glucose load following a meal is the insulin-stimulated glucose transport into the skeletal muscle and adipose tissue. The principal glucose transporter protein that mediates this uptake is the glucose transporter 4 (GLUT4) which is a key regulator of whole-body glucose homeostasis. $\underline{5}$ The GLUT4 remains sequestered intracellularly in the absence of insulin but it quickly translocates to the plasma membrane in presence of insulin. 6 In the early stages of development of type 2 diabetes, impaired glycogen synthesis in muscle is the primary defect responsible for the insulin resistance. 7 Later, it has been shown that impairment of insulinstimulated glucose transport is responsible for resistance to insulin-stimulated glycogen synthesis in muscle in subjects with type 2 diabetes. .8 So, impaired glucose transport plays a major role in the pathogenesis of type 2 diabetes.

GLUT4 protein and gene expression have been extensively studied in skeletal muscle and adipose tissue of type 2 diabetic patients. The 


\begin{tabular}{|c|c|c|c|}
\hline \multicolumn{4}{|c|}{ Table I } \\
\hline \multicolumn{4}{|c|}{ Reverse transcriptase PCR primer sequence } \\
\hline Name & $\begin{array}{l}\text { Accession } \\
\text { number }\end{array}$ & Primer sequence $5^{\prime} \rightarrow 3^{\prime}$ & $\begin{array}{l}\text { Amplification } \\
\text { size (bp) }\end{array}$ \\
\hline GLUT4 & NM_001042.2 & $\begin{array}{l}\text { Forward: } \\
\text { TCTTCGAGACAGCAGGGGTA } \\
\text { Reverse: } \\
\text { CCCATAGCCTCCGCAACATA }\end{array}$ & 400 \\
\hline$\beta$-actin & NM_001101.3 & $\begin{array}{l}\text { Forward: } \\
\text { CTGAAGTACCCCATCGAGC } \\
\text { Reverse: } \\
\text { CCGTGGTGGTGAAGCTGTAG }\end{array}$ & 413 \\
\hline
\end{tabular}

significant reduction in GLUT4 protein and gene expression have been observed in adipocytes from the patients with type 2 diabetes and obesity. .9 More recently, it has been shown that low expression of GLUT4 mRNA in the subcutaneous adipose tissue is associated with insulin resistance and type 2 diabetes mellitus. $\underline{10}$ Another study also showed a significant reduction of GLUT4 protein expression in the skeletal muscle and adipose tissue from the patients with type 2 diabetes mellitus. $\underline{11}$ Since GLUT4 expression and translocation are the final outcome of insulin signaling cascade and GLUT4 level decreases in insulin resistance and type 2 diabetes mellitus, cellular GLUT4 status can be used as an alternate marker for insulin resistance. Unfortunately, GLUT4 measurement in the skeletal muscle and adipose tissue requires invasive tissue biopsy and therefore, is not suitable in large-scale clinical research, longitudinal interventional studies and in clinical practice.

The cells of the peripheral blood are constantly exposed to high glucose in patient with diabetes. Although the blood cells get supply of glucose at a constant rate through insulin-independent GLUT1 and GLUT3, several studies have shown that insulin -dependent GLUT4 is also present in the granulocytes, monocytes and lymphocytes. $12-14$ The GLUT4 levels were found $73 \%$ increased under hypoglycemic conditions in the granulocytes but remained unaffected in the monocytes. $\underline{14}$ Moreover, it has been shown that insulin stimulation increases the translocation of GLUT4 on the plasma membrane of mononuclear cells collected from human subjects. $\underline{15}$

The aims of the present study were to investigate the status of GLUT4 gene expression in peripheral blood leukocytes of type 2 diabetes mellitus patients and to find out its relationship with glycemic, insulinemic and homeostasis model assessmentbased insulin resistance status in those patients with a view to assess the potentiality of GLUT4 gene expression in leukocytes as a simple and suitable marker for insulin resistance.

\section{Materials and Methods}

A total of 48 subjects were recruited from those who came for screening at the outpatient Department, after giving written consent. The subjects were divided into two groups: newly diagnosed type 2 diabetes mellitus group $(n=23)$ and age, sex, body mass index-matched non-diabetic healthy control group $(n=25)$. The subjects having previous history of diabetes or suffering from hypertension, chronic liver and kidney diseases, infection, inflammatory disease and malignancy as well as pregnant and lactating women and regular drug users were excluded.

A detailed medical history was taken, clinical examination including height, weight and blood pressure data were recorded and fasting blood sample was collected after overnight fasting of $>12$ hours from all subjects. With all aseptic precaution, $5 \mathrm{~mL}$ venous blood was collected from the anticubital vein. Fasting glucose, total cholesterol, triglyceride, and HDL cholesterol levels were measured by the enzymatic colorimetric method using Dimension ${ }^{\circledR}$ RxL Max ${ }^{\circledR}$ clinical chemistry analyzer (Siemens Healthcare Diagnostics Inc., USA). Fasting serum insulin levels were measured by microparticle enzyme immunoassay technique (Abbott Diagnostics, Germany) using an Abbott Architect Plus ci4100 system. HbA1c was estimated by ion-exchange high-performance liquid chromatography in a Bio-Rad D-10 instrument (Bio-Rad Laboratories Inc., USA). The insulin resistance and $\beta$-cell function were calculated as homeostasis model assessment of insulin resistance [(glucose $x$ insulin)/22.5] and homeostasis model assessment of $\beta$-cell function (homeostasis model assessment- $\% \mathrm{~B}$ ) $[(20 \times$ insulin $) /($ glucose -3.5$)]$, respectively, where glucose in $\mathrm{mmol} / \mathrm{L}$ and insulin in $\mu \mathrm{U} / \mathrm{mL}$. Insulin sensitivity was calculated by quantitative insulin sensitivity check index QUICKI [1/(log insulin + $\log$ glucose)], where glucose was in $\mathrm{mg} / \mathrm{dL}$ and insulin was in $\mu \mathrm{U} / \mathrm{mL}$. The LDL cholesterol level was calculated by the Friedewald equation.

\section{Extraction of total RNA from peripheral blood leukocytes and reverse transcription}

The total RNA was extracted from the peripheral blood leukocytes by SV total RNA isolation system (Promega, USA) according to the manufacturer's instructions. As a part of the extraction process, the sample was treated with DNase-I to remove genomic DNA contamination. The amount of extracted RNA was quantified by spectrophotometry at $260 \mathrm{~nm}$ using NanoPhotometer ${ }^{\circledR}$ P300 (Implen $\mathrm{GmbH}$, Germany). The purity of RNA was assessed by the ratio of absorbance at 260 and 280 $\mathrm{nm}$ (A260/A280) and also by the ratio of absorbance at 260 and $230 \mathrm{~nm}$ (A260/A230). RNA sample with absorbance ratio ranging from 1.8 to 2.2 was used. The extracted RNA sample was stored at $-80^{\circ} \mathrm{C}$ until further analysis. 
Table II

Characteristics of the study subjects

\begin{tabular}{|c|c|c|c|}
\hline Variables & $\begin{array}{l}\text { Control } \\
\text { group } \\
(\mathrm{n}=25)\end{array}$ & $\begin{array}{l}\text { Diabetic } \\
\text { group } \\
(n=23)\end{array}$ & $\mathrm{p}$ value \\
\hline Age (years) & $40.6 \pm 8.0$ & $43.8 \pm 6.7$ & 0.17 \\
\hline Male & 14 & 12 & --- \\
\hline Female & 11 & 11 & -- \\
\hline Height (m) & $1.6 \pm 0.1$ & $1.6 \pm 0.1$ & 0.84 \\
\hline Weight (kg) & $65.3 \pm 8.6$ & $64.5 \pm 8.9$ & 0.79 \\
\hline Body mass index $\left(\mathrm{kg} / \mathrm{m}^{2}\right)$ & $24.2 \pm 2.3$ & $24.1 \pm 2.6$ & 0.89 \\
\hline Systolic blood pressure (mm Hg) & $122 \pm 8$ & $124 \pm 8$ & 0.45 \\
\hline Diastolic blood pressure (mm Hg) & $83 \pm 5$ & $81 \pm 7$ & 0.38 \\
\hline Alanine amino transferase $(\mathrm{U} / \mathrm{L})$ & $33 \pm 14$ & $39 \pm 15$ & 0.14 \\
\hline Creatinine (mg/dL) & $0.8 \pm 0.1$ & $0.8 \pm 0.1$ & 0.43 \\
\hline Total cholesterol (mg/dL) & $183 \pm 24$ & $206 \pm 39$ & 0.03 \\
\hline Triglyceride (mg/dL) & $154 \pm 53$ & $181 \pm 41$ & 0.08 \\
\hline $\begin{array}{l}\text { High density lipoprotein-cholesterol } \\
(\mathrm{mg} / \mathrm{dL})\end{array}$ & $36 \pm 8$ & $37 \pm 7$ & 0.94 \\
\hline $\begin{array}{l}\text { Low density lipoprotein-cholesterol } \\
(\mathrm{mg} / \mathrm{dL})\end{array}$ & $117 \pm 31$ & $127 \pm 42$ & 0.42 \\
\hline Fasting glucose (mmol/L) & $4.8 \pm 0.7$ & $10.0 \pm 3.6$ & $<0.001$ \\
\hline HbA1c (\%) & $4.9 \pm 0.5$ & $8.4 \pm 2.0$ & $<0.001$ \\
\hline Fasting insulin $(\mu \mathrm{U} / \mathrm{mL})$ & $9.8 \pm 4.3$ & $10.3 \pm 5.3$ & 0.71 \\
\hline
\end{tabular}

Table III

Insulin resistance, $\beta$-cell function and insulin sensitivity of study subjects

\begin{tabular}{|lrrr|}
\hline Variables & $\begin{array}{r}\text { Control group } \\
(\mathrm{n}=25)\end{array}$ & $\begin{array}{r}\text { Diabetic group } \\
(\mathrm{n}=23)\end{array}$ & $\mathrm{p}$ value \\
\hline HOMA-IR & 2.0 & 3.7 & 0.002 \\
& $(1.3-2.9)$ & $(2.4-6.4)$ & \\
HOMA-\%B & $157(106-233)$ & $43(13-73)$ & $<0.001$ \\
QUICKI & $0.4 \pm 0.0$ & $0.3 \pm 0.0$ & 0.001
\end{tabular}

Data are expressed in median (inter-quartile range) for HOMA-IR and HOMA-\%B, and in mean \pm SD for QUICKI. Comparison between groups was done by Mann-Whitney U-test for HOMA-IR and HOMA-\%B, and by unpaired t-test for QUICKI. HOMA-IR, ${ }^{*} \mathrm{p}=0.002$ versus control group. HOMA- $\% \mathrm{~B}, \mathrm{p}<0.001$ versus control group. HOMA-IR, homeostasis model assessment of insulin resistance; HOMA-\%B, homeostasis model assessment of beta cell function; QUICKI, quantitative insulin sensitivity check index.

\section{Semi-quantitative reverse transcriptase PCR}

The extracted RNA samples were then converted to cDNA using the GoScript ${ }^{\mathrm{TM}}$ reverse transcription system (Promega, USA), according to manufacturer's instruction, and was stored at $-20^{\circ} \mathrm{C}$ until used for PCR. The cDNA samples were subjected to PCR to for semi-quantification of the transcripts (mRNA) of GLUT4 using the GoTaq ${ }^{\circledR}$ G2 HotStart colorless master mix (Promega, USA) and target- specific primers for GLUT4 and $\beta$-actin. The $\beta$-actin was used as a reference gene or internal control to ensure the quality of cDNA and normalize GLUT4 mRNA expression. The primers (Table I) were designed based on the GenBank sequence database using the Primer-BLAST software tool. The PCR reactions were performed using a thermal cycler (Mastercycler nexus, Eppendorf, Germany) with initial denaturation at $95^{\circ} \mathrm{C}$ for $2 \mathrm{~min}$, followed by 40 cycles of $94^{\circ} \mathrm{C}$ for $30 \mathrm{sec}, 56^{\circ} \mathrm{C}$ for $60 \mathrm{sec}$ and $72^{\circ} \mathrm{C}$ for $30 \mathrm{sec}$ for GLUT4 and 30 cycles of $94^{\circ} \mathrm{C}$ for 30 sec, $55^{\circ} \mathrm{C}$ for $60 \mathrm{sec}$ and $72^{\circ} \mathrm{C}$ for $30 \mathrm{sec}$ for $\beta$-actin. These cycling conditions and the specificity of PCR products were initially validated by agarose gel electrophoresis of the PCR products. Gel electrophoresis of the PCR products was done in $1.5 \%$ agarose gel at $80 \mathrm{~V}$ for around $30 \mathrm{~min}$ followed by staining in ethidium bromide solution for 15 min. The gel was exposed to UV ray and the image was captured in a gel documentation system UVDI312 (Major Science, USA). The optical density of each band in the gel image was analyzed by NIH image analysis software Image J. The optical density ratio of GLUT4 to $\beta$-actin was considered as relative expression of GLUT4.

\section{Statistical analysis}

Data are presented as mean \pm standard deviation (SD) or median (inter-quartile range) and analyzed by unpaired Student's t-test to compare the GLUT4 gene expressions between groups. The correlations of GLUT4 gene expression with homeostasis model assessment-insulin resistance and other variables were determined by Spearman's correlation analysis. A two-tailed value of $\mathrm{p}<0.05$ was considered statistically significant.

\section{Results}

The study subjects were similar in terms of age, gender distribution, height, weight, body mass index, systolic and diastolic blood pressure, renal functions and hepatic functions (Table II). The fasting blood glucose level and HbA1c were found significantly $(p<0.001)$ elevated in the newly diagnosed type 2 diabetic group compared to the control group, as expected. However, the insulin level did not show any significant difference between the control and diabetic groups. Moreover, the total cholesterol level was found significantly elevated in diabetic group compared with control group $(p<0.03)$ whether the triglyceride, high density lipoprotein-cholesterol and low density lipoproteincholesterol levels were found similarities between the two groups.

\section{Insulin resistance, beta cell function and insulin sensitivity}

The median (interquartile range) HOMA-IR value 
Table IV

Correlation of Glut4 gene expression with fasting glucose, HbA1c, insulin and insulin resistance

\begin{tabular}{|lccccccc|}
\hline Parameter & $\begin{array}{c}\text { All } \\
\text { subjects }\end{array}$ & $\begin{array}{c}\text { All sub- } \\
\text { jects }\end{array}$ & $\begin{array}{c}\text { Diabetic } \\
\text { group }\end{array}$ & $\begin{array}{c}\text { Diabetic } \\
\text { group }\end{array}$ & $\begin{array}{c}\text { Control } \\
\text { group }\end{array}$ & $\begin{array}{c}\text { Control } \\
\text { group }\end{array}$ \\
\hline \multicolumn{1}{|c}{} & $\mathrm{r}$ & $\mathrm{p}$ & $\mathrm{r}$ & $\mathrm{P}$ & $\mathrm{r}$ & $\mathrm{p}$ \\
Glucose & -0.25 & 0.09 & -0.26 & 0.26 & -0.03 & 0.88 \\
HbA1c & -0.21 & 0.17 & -0.19 & 0.41 & 0.17 & 0.44 \\
Insulin & -0.36 & 0.018 & -0.30 & 0.19 & -0.41 & 0.047 \\
HOMA-IR & -0.35 & 0.02 & -0.31 & 0.19 & -0.34 & 0.11 \\
\hline
\end{tabular}

Relative expression of Glut4 gene was measured as a ratio of the optical densities of Glut 4 to beta-actin PCR products on $1.5 \%$ agarose gel. Correlations of Glut4 gene expression with fasting glucose, $\mathrm{HbA1c}$, insulin and insulin resistance were measured by Pearson's correlation. HOMA-IR, homeostasis model assessment of insulin resistance; r, Pearson's correlation coefficient diabetic group showed a decreased level of GLUT4 gene expression, no statistically significant difference $(p=0.16)$ was found between the control $(0.45 \pm$ $0.1)$ and the diabetic groups $(0.41 \pm 0.08)$.

GLUT4 gene expression in relationship to fasting glucose, $\mathrm{HbA1c}$, insulin and insulin resistance in diabetic patients

To identify the factors related with GLUT4 gene expression, Pearson's correlation test was performed to see whether relative expression of GLUT4 gene expression correlates with fasting glucose, $\mathrm{HbA1c}$, insulin and insulin resistance. As shown in Table IV, when all the study subjects were considered, GLUT4 gene expression showed a negative trend with fasting glucose $(p=0.09)$ and HbA1c ( $p=0.17$, but it was significantly correlated with insulin $(p=0.018)$ and insulin resistance $(p=$ $0.02)$. However, when diabetic or control group was separately considered, those correlations became insignificant except that the negative correlation with insulin level which was marginally significant at $\mathrm{p}=0.047$. (interquartile range) of beta cell function HOMA-\% $B$, was found significantly decreased $(p<0.001)$ in the diabetic group compared to the control group (Table III). Insulin sensitivity was assessed by quantitative insulin sensitivity check index, QUICKI, and it was found markedly decreased $(p=0.001)$ in the diabetic group compared to the control group (Table III).

\section{GLUT4 gene expression in peripheral blood leukocytes}

Relative expressions of GLUT4 gene in peripheral blood leukocytes were semi-quantitatively determined by GLUT4 to $\beta$-actin ratio of the optical densities of the PCR products in $1.5 \%$ agarose gel and mean \pm standard deviation (SD) values of GLUT4 gene expression in the control and diabetic groups were shown in Figure 1. Although the

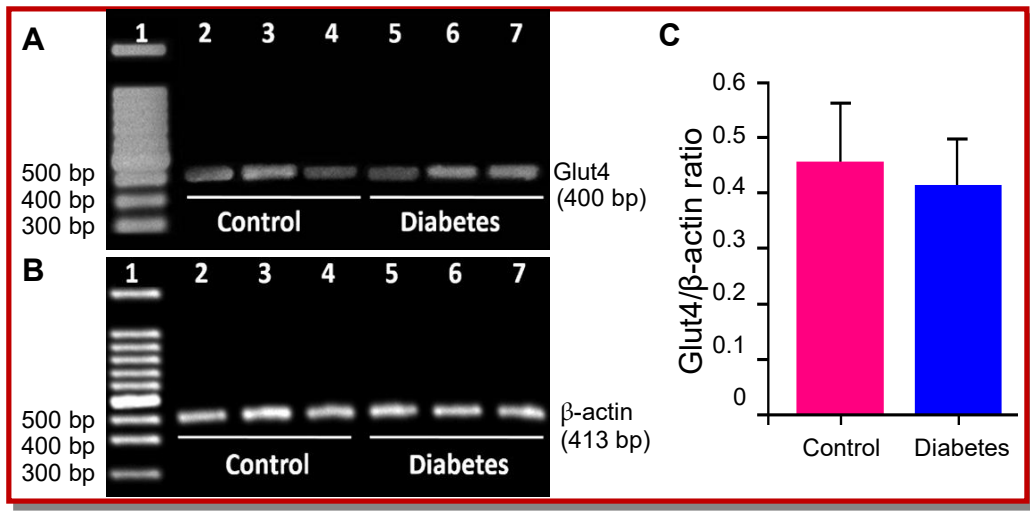

Figure 1: Representative photomicrographs of agarose gel electrophoresis of GLUT4 (A) and $\beta$-actin (B) PCR products. Amplification size of GLUT4 and $\beta$ actin expressions are $400 \mathrm{bp}$ and $413 \mathrm{bp}$ respectively. Relative expression of GLUT4 gene was expressed as GLUT4 to $\beta$-actin ratio of the optical densities of the PCR products in $1.5 \%$ agarose gel. The bar diagram $(C)$ shows the mean \pm SD of GLUT4/ $\beta$-actin ratio in control and newly diagnosed type 2 diabetic patients

\section{Discussion}

The diabetic group of this study showed marked hyperglycemia, insulin resistance and beta-cell dysfunction. However, the GLUT4 gene expression did not differ significantly between diabetic and control subjects. Never the less, in the present study, the diabetic group showed a relatively lower level of GLUT4 gene expression and a negative trend in the relationship with fasting glucose, $\mathrm{HbA1c}$, insulin and insulin resistance.

Whenever an individual is diagnosed as having diabetes mellitus, he or she usually starts medication, dietary intervention or exercise, as suggested by the physician. These factors, whether it is medication, dietary intervention or exercise, have the ability to modify insulin resistance/sensitivity and/or insulin secretory capacity and thereby altering GLUT4 gene expression. $\underline{14}$ Therefore, only newly diagnosed (or previously undiagnosed) type 2 diabetic patients, and age, sex and BMI-matched non-diabetic control subjects were included in this study. Thus the findings of this study are most likely due to hyperglycemia and/or insulin resistance associated with diabetes mellitus.

The GLUT4 remains sequestered intracellularly which quickly translocates to plasma membrane in the presence of insulin. 6 The GLUT4 is highly expressed in skeletal muscle and adipose tissue and impaired glucose uptake by the adipose tissue and skeletal muscle from the peripheral blood is an important mechanism of hyperglycemia in diabetes mellitus, therefore, GLUT4 deficiency or defective GLUT4 translocation is responsible for that. 
Therefore, the GLUT4 protein and gene expression and GLUT4 translocation to the plasma membrane have been extensively studied in skeletal muscle and adipose tissue of type 2 diabetic patients. Significant reduction in GLUT4 protein and gene expression were observed in adipocytes from patients with type 2 diabetes and obesity. 9 However, one study showed unaltered GLUT4 protein and gene expression in skeletal muscle in insulinresistant diabetic patients, 16 whether another study showed significant reduction of GLUT4 protein expression in skeletal muscle and adipose tissue from patients with type 2 diabetes mellitus.11 In a recent study, low expression of GLUT4 mRNA in subcutaneous adipose tissue was observed to be associated with insulin resistance and type 2 diabetes mellitus. 10

The cells of the peripheral blood are constantly exposed to high glucose in patients with diabetes. Although several studies have shown that insulindependent GLUT4 is present in granulocytes, monocytes and lymphocytes, the blood cells get supply of glucose at a constant rate through insulinindependent GLUT1 and GLUT3.12-14 Therefore, the expression pattern of GLUT4 in peripheral blood leukocytes is unlikely to be comparable with that of adipose tissue or skeletal muscle where GLUT4 is the most important glucose transporter and plays important role in cellular glucose uptake.

Many studies investigated GLUT4 protein expression and its translocation to the plasma membrane of peripheral blood leucocytes and its regulation by insulin. It has been shown that the GLUT4 levels markedly increase under hypoglycemic conditions in granulocytes but remain unaffected in monocytes. $\underline{14}$ Moreover, it has been observed that insulin stimulation increases the translocation of GLUT4 protein on the plasma membrane of mononuclear cells collected from human subjects. 15 Overexpression of GLUT4 protein in the plasma membrane of peripheral blood leukocytes is also noted among subjects with positive family history of diabetes. 17 However, to our knowledge, no study has been found to identify the status of GLUT4 gene expression in peripheral blood leukocytes as all these mentioned studies measured only GLUT4 protein levels by flow cytometry. Kipmen-Korgun et al. $\underline{18}$ previously measured GLUT4 gene expression by PCR in peripheral blood leukocytes of type 2 diabetic patients and found no significant alteration of GLUT4 mRNA level in diabetes which is similar to the findings of our present study. But the finding of Kipmen-Korgun et al. was not convincing because $35 \%$ of the diabetic patients of their study had been taking insulin. Thus the effects of insulin, diet or other medications on GLUT4 gene expression cannot be excluded. From that point of view, it may be claimed that our present finding, although similar to that of Kipmen-Korgun et al. derived from a well-designed study and thus the findings are more convincing.

To our knowledge, we did not find any previous study that showed a relationship of leukocyte GLUT4 gene expression and fasting glucose, $\mathrm{HbA1c}$, insulin or insulin resistance. Thus we for the first time showed a negative trend in the relationship of GLUT4 gene expression with fasting glucose, $\mathrm{HbA} 1 \mathrm{c}$, insulin and insulin resistance in diabetic patients. In fact, when the diabetic and control subjects were taken together in the analysis, GLUT4 gene expression showed significant negative correlation with fasting insulin level and insulin resistance status. These findings suggest that decreased GLUT4 gene expression in peripheral blood leukocytes is associated with insulin resistance. However, experimental studies in animal models and cell culture with appropriate inducers and inhibitors will be required to explore the underlying molecular mechanism of decreased expression of GLUT4 in the peripheral blood leukocytes of individuals with higher IR. However, the findings of the present study are not strong enough to suggest the potential clinical use of GLUT4 gene expression as a marker of insulin resistance.

The present study has several limitations. Most important limitations are relatively small sample size and cross-sectional nature of the study. We also admit that the measurement of GLUT4 protein levels in the cytoplasm and plasma membrane of peripheral blood leukocytes would have been supportive to ascertain whether GLUT4 gene expression pattern shown in our study correlates with translation, post-translational modification and translocation of GLUT4. Furthermore, we used reverse transcription PCR technique to measure GLUT4 gene expression which is at best semiquantitative, hence it is important to do real-time qPCR to confirm our present finding.

\section{Conclusion}

GLUT4 gene expression in the peripheral blood leukocytes, although decreases slightly, do not significantly alter in newly diagnosed type 2 diabetic patients compared to the control subjects. Furthermore, GLUT4 gene expression shows a negative trend in the relationship with fasting glucose, HbA1c, insulin and insulin resistance in diabetic patients.

\section{Ethical Issue}

This study was conducted according to the Declaration of Helsinki and was approved by the Institutional Review Board of the Bangabandhu Sheikh Mujib Medical University. 


\section{References}

1. American Diabetic Association. Diagnosis and classification of diabetes mellitus. Diabetes Care. 2014; 37: S81-90.

2. Matthews DR, Hosker JP, Rudenski AS, Naylor BA, Treacher DF, Turner RC. Homeostasis model assessment: Insulin resistance and BETA-cell function from fasting plasma glucose and insulin concentrations in man. Diabetologia 1985; 28: 412 19.

3. Xiang AH, Watanabe RM, Buchanan TA. HOMA and Matsuda indices of insulin sensitivity: Poor correlation with minimal model-based estimates of insulin sensitivity in longitudinal settings. Diabetologia 2014; 57: 334-38.

4. Ader M, Stefanovski D, Richey JM, Kim SP, Kolka $\mathrm{CM}$, Ionut V, Kabir M, Bergman RN. Failure of homeostatic model assessment of insulin resistance to detect marked diet-induced insulin resistance in dogs. Diabetes 2014; 63: 1914-19.

5. Huang S, Czech MP. The GLUT4 glucose transporter. Cell Metab. 2007; 5: 237-52.

6. Shepherd PR, Kahn BB. Glucose transporters and insulin action: Implications for insulin resistance and diabetes mellitus. N Engl J Med. 1999; 341: 248 57.

7. DeFronzo RA. Pathogenesis of type 2 diabetes: Metabolic and molecular implications for identifying diabetes genes. Diabetes Rev. 1997; 5: 177-269.

8. Cline GW, Petersen KF, Krssak M, Shen J, Hundal RS, Trajanoski Z, Inzucchi S, Dresner A, Rothman $\mathrm{DL}$, Shulman GI. Impaired glucose transport as a cause of decreased insulin-stimulated muscle glycogen synthesis in type 2 diabetes. N Engl J Med. 1999; 341: 240-46.

9. Garvey WT, Maianu L, Huecksteadt TP, Birnbaum MJ, Molina JM, Ciaraldi TP. Pretranslational suppression of a glucose transporter protein causes insulin resistance in adipocytes from patients with non-insulin-dependent diabetes mellitus and obesity. J Clin Invest. 1991; 87: 1072-81.

10. Kouidhi S, Berrhouma R, Rouissi K, Jarboui S, Clerget-Froidevaux MS, Seugnet I, Bchir F, Demeneix B, Guissouma H, Elgaaied AB. Human subcutaneous adipose tissue GLUT4 mRNA expression in obesity and type 2 diabetes. Acta Diabetol. 2013; 50: 227-32.

11. Kampmann U, Christensen B, Nielsen TS, Pedersen SB, Orskov L, Lund S, Moller N, Jessen N. GLUT4 and UBC9 protein expression is reduced in muscle from type 2 diabetic patients with severe insulin resistance. PLoS One. 2011; 6: e27854.

12. Schwartz RH, Bianco AR, Handwerger BS, Kahn CR. Demonstration that monocytes rather than lymphocytes are the insulin-binding cells in preparations of human peripheral blood mononuclear leukocytes: Implications for studies of insulinresistant states in man. Proc Natl Acad Sci. 1975; 72 474-78.

13. Chakrabarti R, Jung CY, Lee TP, Liu H, Mookerjee BK. Changes in glucose transport and transporter isoforms during the activation of human peripheral blood lymphocytes by phytohemagglutinin. J Immunol. 1994; 152: 2660-68.

14. Korgun ET, Demir R, Sedlmayr P, Desoye G, Arikan G, Puerstner P, Haeusler M, Dohr G, Skofitsch G, Hahn T. Physiological leukocytosis during pregnancy is associated with changes in glucose transporter expression of maternal peripheral blood granulocytes and monocytes. Am J Reprod Immunol. 2002; 48: 110-16.

15. Maratou E, Dimitriadis G, Kollias A, Boutati E, Lambadiari V, Mitrou P, Raptis SA. Glucose transporter expression on the plasma membrane of resting and activated white blood cells. Eur J Clin Invest. 2007; 37: 282-90.

16. Garvey WT, Maianu L, Hancock JA, Golichowski AM, Baron A. Gene expression of GLUT4 in skeletal muscle from insulin-resistant patients with obesity, IGT, GDM, and NIDDM. Diabetes 1992: 41: 465-75.

17. Bernat-Karpińska M, Czech A, Piatkiewicz P, Wierzbicki P, Górski A. Cellular glucose transport disturbances as a marker of the pre-diabetic state: Pathogenetic and clinical significance of the assessment of GLUT4 expression. Endokrynol Pol. 2010; 61: 269-74.

18. Kipmen-Korgun D, Bilmen-Sarikcioglu S, Altunbas H, Demir R, Korgun ET. Type-2 diabetes downregulates glucose transporter proteins and genes of the human blood leukocytes. Scand J Clin Lab Invest. 2009; 69: 350-58. 